
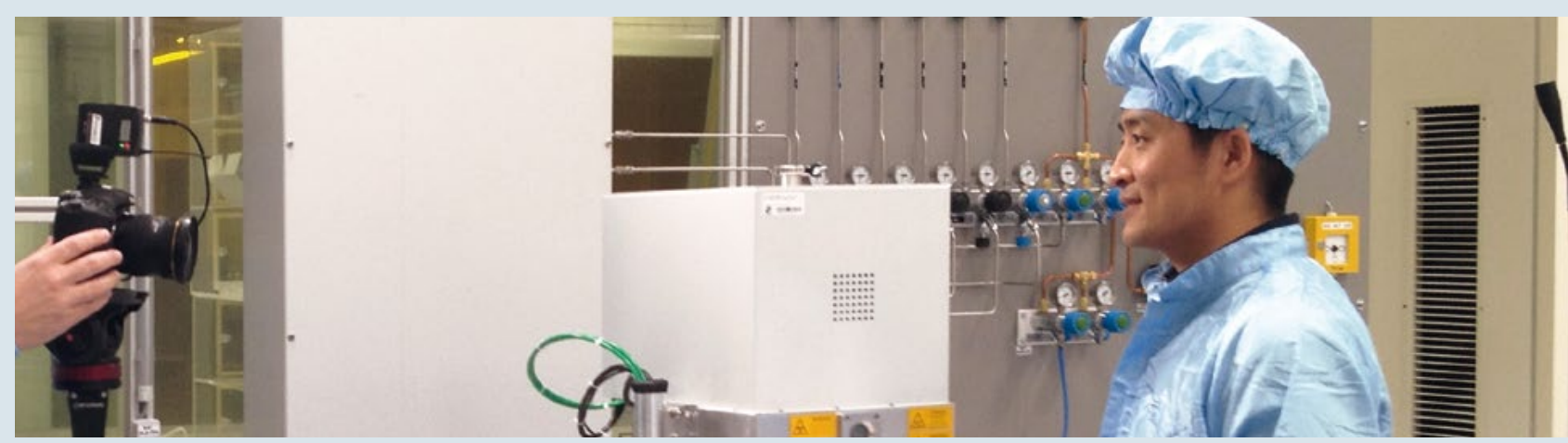

\title{
Make it visible
}

\section{Scientific videos on Beilstein TV}

Sometimes written words are not enough. To explain increasingly complex research results text and graphics often reach the limits of what can be represented. It is here that Beilstein TV bridges the gap for a clearer understanding by merging of presentation, animation and documentation into a single sequence. Moreover, the visual preparation draws a portrait of the scientists and allows an insight into his or her ways of thinking and working.

Launched in 2010, Beilstein TV is a professionally produced scientific video portal providing full free access to the public without restrictions. The videos range from research laboratory experiments and lectures to interviews with scientists. Most videos of Beilstein TV are related to articles in the Beilstein journals. Therefore, special topics of organic chemistry or nanotechnology are particularly well represented. The videos add important visual or verbal aspects to scientific findings presented in articles. Series of videos cover cutting-edge topics with promising applications like glycoscience or nanomaterials. Highlights include videos with Professor Stefan Hecht from the Humboldt-Universität in Berlin explaining molecules that can be switched by light or biomimetic materials derived from snake skins, explained by Professor Stanislav N. Gorb at Kiel University in Germany. Professor Steven V. Ley introduces the Innovative Technology Centre at the University of Cambridge in the United Kingdom. This "lab of the future" demonstrates the incorporation of new technologies, such as flow chemistry, into organic chemistry.

Volker Lange is responsible for the production of scientific videos at the Beilstein-Institut and answers frequently asked questions about the video production:

\section{Why do you produce science videos?}

Traditionally the exchange of scientific ideas is strongly based on written publications. Some scientific findings, however, are better explained by a video than with letters and drawings. Science is not only about facts - it is also about the people performing high-quality research in laboratories. We regard videos as a modern communication tool which is becoming increasingly important in science.

\section{Who watches the videos?}

Most of our videos deal with topics requiring advanced scientific knowledge. Our target audience ranges from students in higher semesters and Ph.D. students to established scientists. Recently, we were very pleased to learn that some videos are also used in upper intermediate courses in schools to support teaching.

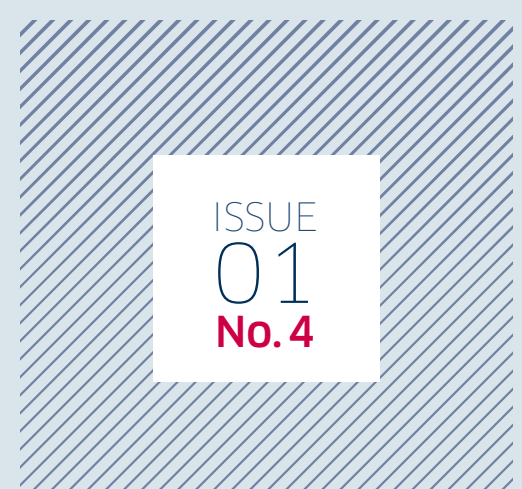

\section{How can a scientist participate in Beilstein TV?}

Often, the first contact with scientists is made when they publish an article in one of our journals or when they attend one of our symposia. But we are of course happy to receive suggestions for interesting topics from any research group. Scientists are always welcome to contact us. 


\begin{abstract}
Volker Lange (right),
filmmaker of the Beilstein-
Institut, interviews Professor
Hermann A. Wegner at Giessen
University to prepare the
production of videos on chemical
catalysts.

\section{What is needed to} produce a video?

Today, nearly everybody has a video camera with good resolution at hand: a smartphone. Although this device can be used for filming everyday scenes, the camera is not sufficient to produce high-quality videos. For high-quality videos supplementary lighting, good sound, professional editing, camera work, and above all, a good concept for explaining the scientific content is required. Since the scientific videos are part of our funding projects, we cover all production costs.
\end{abstract}

\section{What is the first step?}

Every video starts with an idea: An exciting topic is proposed by a research group leader. Then, I visit the research group in its facilities and discuss the important aspects for the video. Together, we are planning the script and discuss details of the shooting: Which laboratory locations will be used for the individual scenes? Which scientists will be filmed? How are the facts presented? Shall an animation be added? How long will the video be?, etc. We usually aim to produce videos with a lengths of 5 to 7 minutes.

\section{How does the shooting day look like?}

The professional camera team, who is also responsible for light and sound, joins me at the shoot-

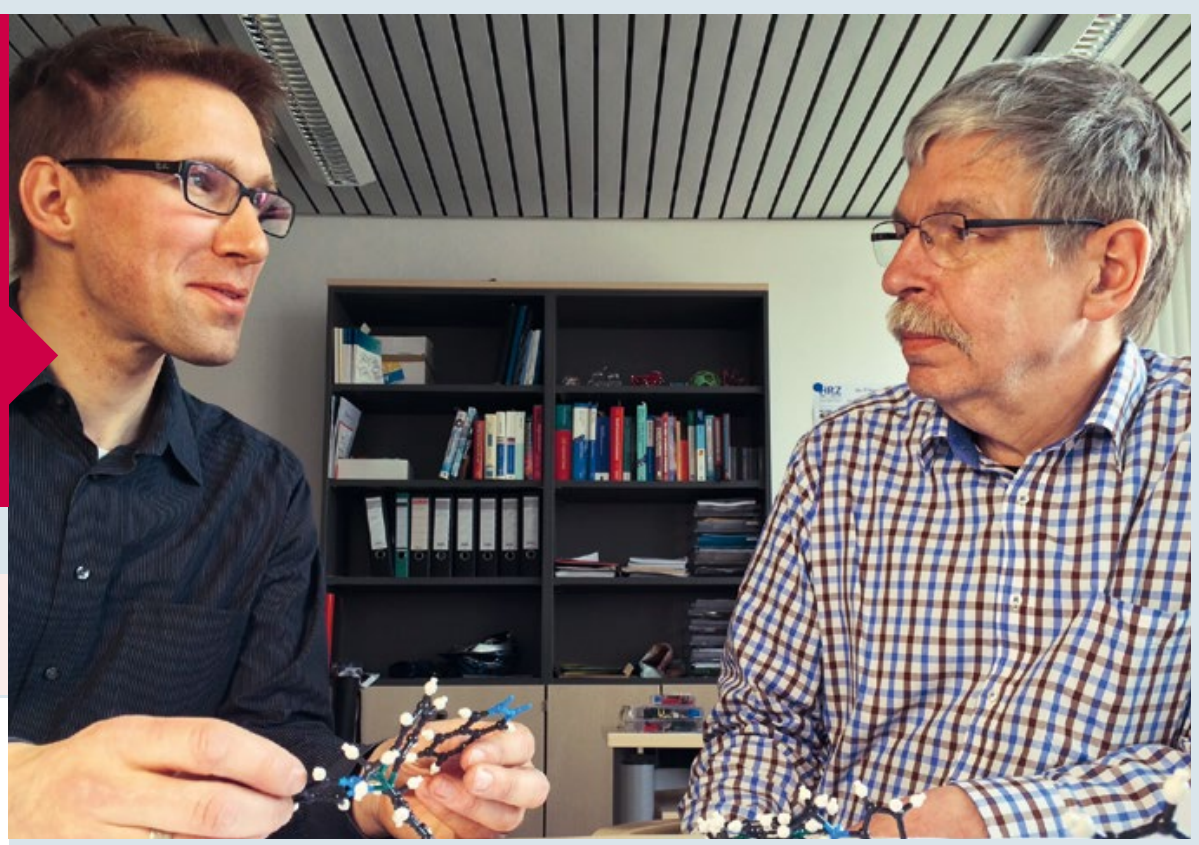

ing location and we discuss remaining uncertainties or questions. On the set the film crew often has to deal with difficult demands of a laboratory. However, even if a video deals with very complex facts, the shooting is usually finished within one day.

Before the first scene can be filmed, the shooting script has to be discussed in detail and the technical equipment must be set up. When lighting, sound and camera settings meet the requirements of the film crew, the actors come into play. Usually, the director of a research group introduces the topic with an overview explanation and co-workers reveal details of their work in the laboratory, for example, they demonstrate how a certain experiment is performed.

\section{What is done after the shooting?}

In most cases, different versions of individual scenes are shot with

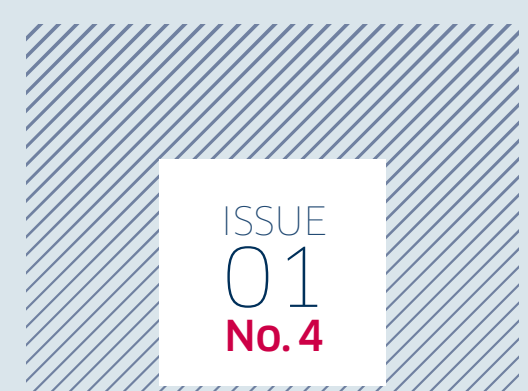

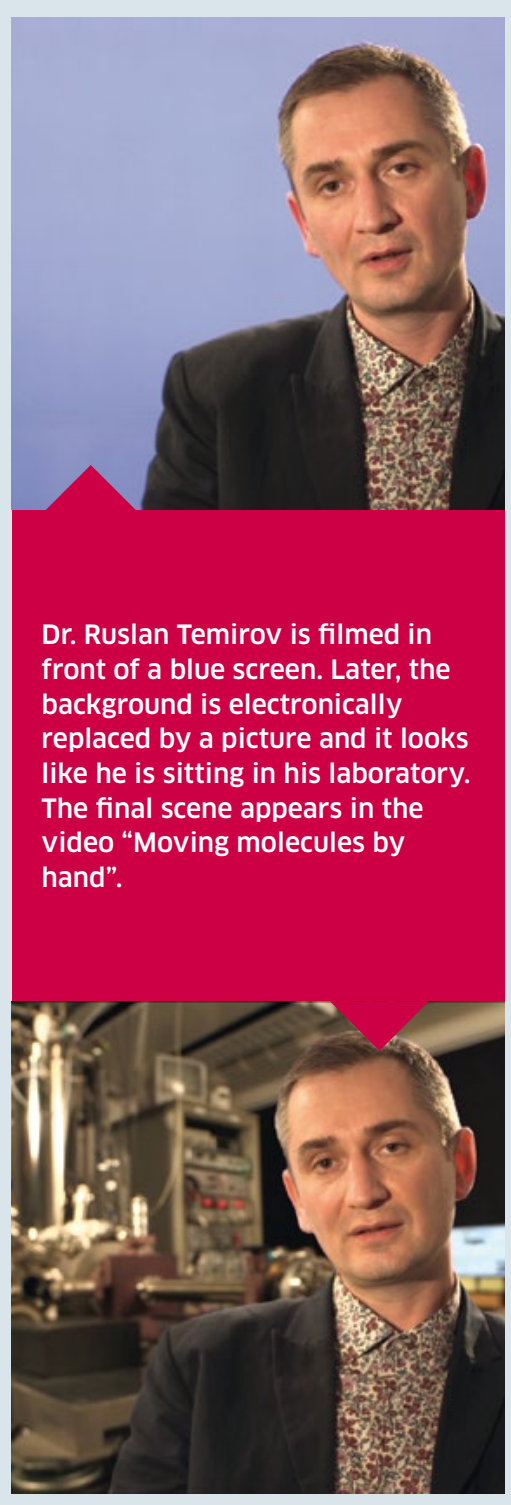


different camera settings. During the post-production the best scenes are selected and compiled into a rough cut of the video. In a next step, the researchers check that all scientific aspects are correct; for example, that all closeup scenes are assigned to the right voice-over texts. Then the final cut is made and the video is published on www.beilstein. tv. In addition, scientists are of course invited to present the video on their own website and share it with colleagues via social media. The video is published in most cases - a few weeks after the shooting day.

\section{Do you use special effects?}

We often use special film techniques to overcome limitations on the film set or to visualize complex scientific themes, e.g. the blue screen technique and animations. When the blue screen technique is used, a person is filmed in front of a pure blue or green background which later is electronically replaced by an image, a movie or an animation. This technique can also be used to compensate the lack of space in a laboratory: The laboratory can be filmed with a wide-angle lens, while the talking person is recorded in front of a blue screen in regular distance and with a normal lens to avoid any distortions.

\section{How do you make use of animations?}

For example, it is not possible to actually film an electron being accelerated. So we had to find a solution that would show this in an easily understandable way. This is a typical problem which can be solved by animation. The explanations and statements are converted into simple drawings. The animation is usually filmed live, giving the impression that the drawings come to life.
Another example of animation is a molecule as a pot-bellied cartoon character that can be seen in one of our videos about photoswitches. In this case, the animation was created using a computer. While this saves time - because not all of the graphical elements have to be drawn - it also requires a lot of experience in dealing with the animation program and a good sense of timing to let the generated motion sequence look smooth and natural.

\section{What can we expect for the future?}

Up to now, we have published more than 120 videos on Beilstein TV. About every two weeks a new one is added. We have some interesting and hot topics in our production pipeline. You should visit www.beilstein.tv regularly to watch the latest videos!

\section{Author}

Dr. Michael Penk

$\bowtie$ magazine@beilstein-institut.de

\section{Copyright}

doi: 10.3762/bmag.4.

(C) 2015 The authors.

Published by Beilstein-Institut.

This is an open access article under the CC BY license (http:// creativecommons.org/licenses/ by/4.0). This article is part of Issue 1 of the Beilstein Magazine. Copyright by Beilstein-Institut.

www.beilstein-institut.de

Published online 16/10/2015

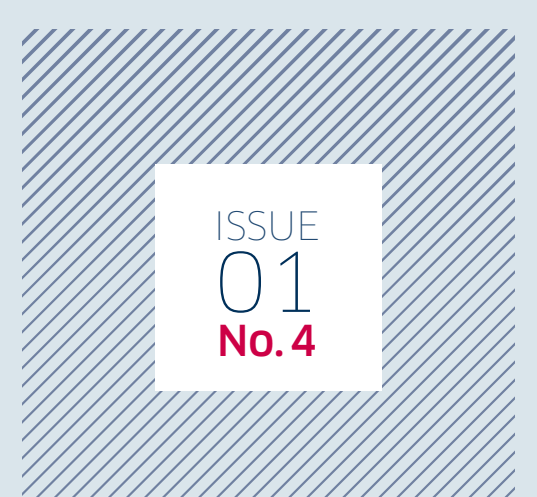

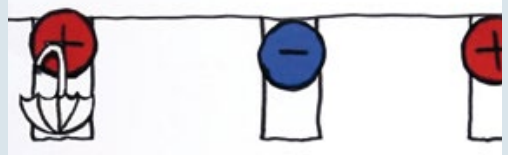

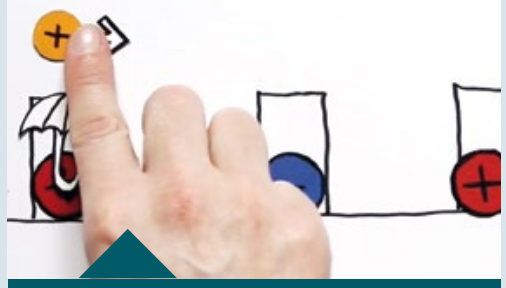

Animation is used to explain how magnetic fields are used to accelerate electrons by attracting and repelling them in rapid succession. The video "Particle accelerators - one for all elements" was filmed at the GSI Helmholtz Centre for Heavy Ion Research in Darmstadt, Germany. (illustration: Ilka Brosch)

A musical molecule plays the piano in the video „How do photoswitches work?". In this video clip Professor Stefan Hecht explains how light changes molecules - without sophisticated chemical formulae or physical equations.

(illustration: Ilka Brosch)

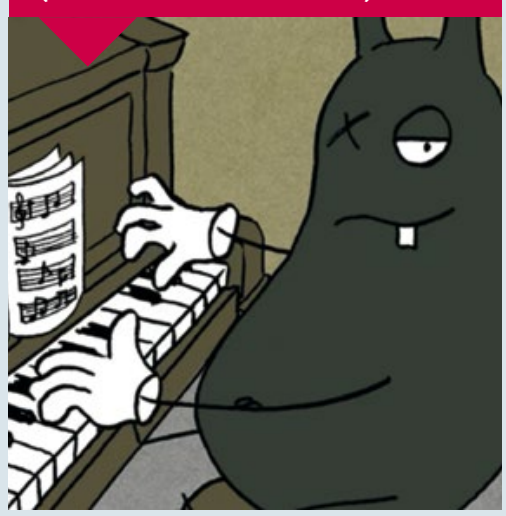

